Article

\title{
Minimum Quantity Lubrication and Carbon Footprint: A Step towards Sustainability
}

\author{
Muhammad Omair ${ }^{1}$, Biswajit Sarkar ${ }^{1, *}$ and Leopoldo Eduardo Cárdenas-Barrón ${ }^{2}$ \\ 1 Department of Industrial \& Management Engineering, Hanyang University, Ansan 15588, \\ Gyeonggi-do, Korea; muhamad.omair87@gmail.com \\ 2 Department of Industrial and Systems Engineering, School of Engineering, Tecnológico de Monterrey, \\ E. Garza Sada 2501 Sur, Monterrey C.P. 64849, Nuevo León, Mexico; lecarden@itesm.mx \\ * Correspondence: bsbiswajitsarkar@gmail.com; Tel.: +82-10-74981981
}

Academic Editor: Matthias Finkbeiner

Received: 27 November 2016; Accepted: 19 April 2017; Published: 29 April 2017

\begin{abstract}
In today's world, there is an increasing awareness among consumers for demanding sustainable products. Several countries have already started working to create strategies for implementing sustainable manufacturing. Other countries are making efforts to access international markets and face intense market competitions in terms of sustainable status of products, which build a huge pressure on manufacturers to avail the concept of sustainable manufacturing. This paper proposes a manufacturing model to minimize total cost of manufacturing and carbon emissions with the effect of variable production quantity to provide sustainable manufacturing. Total cost of manufacturing includes fixed costs and variable costs with the addition of cost of minimum quantity lubrication and imperfect quality items. Minimum quantity lubrication system is an eco-friendly and sustainable, which reduces negative impact on environment and improves workers' safety. This study considers the real situation of imperfect products and proportion of it can be reworked at certain known rate. Numerical example and sensitivity analysis are given by using multiobjective genetic algorithm and goal attainment techniques to illustrate the practical applications of the proposed model.
\end{abstract}

Keywords: sustainable manufacturing; carbon footprint; minimum quantity lubrication; multiobjective optimization; imperfect production

\section{Introduction}

Previously, the manufacturing sector challenged a lot of problems regarding economics, quality, and environment. Initially, the main aim of industries was minimization of costs. In the 1960s, the quality of products became the objective, then customer satisfaction was considered as a significant factor [1]. With the passage of time, the customer started to search for user-friendly, eco-friendly, and sustainable products, which put pressure on manufacturers to develop new techniques and systems to compete for market share. As a result, Material Requirement Planning (MRP), Just In Time (JIT), lean manufacturing, and sustainable manufacturing system were developed [2]. The manufacturing sector needs to move towards sustainability of the economy and achieve the Millennium Development Goals (MDGs), derived from the United Nations Declaration in 2000s [3]. Sustainable manufacturing has increased the value of sustainability and is measured as one of the focused areas of the MDGs to avoid sufferings of future generations $[4,5]$. Sustainability is associated with the triple bottom line (TBL) framework, consists of social, environmental, and economic indicators. Marques et al. proposed a framework to assess the sustainability of urban water services in Portugal by adding dimensions of assets and governance in TBL framework [6]. Sustainable manufacturing is defined as to manufacture 
products by certain processes, which use minimum resources and renewable energies, produce less negative impact on environment, are safe for humans, and economically well [7].

Environmentally, the ecosystem is affected largely because of Greenhouse Gas Emission (GHG) from burning of fuel in manufacturing and services activities, which are commonly used to fulfill energy demand [8]. The carbon footprint (CFP) is the measure of carbon dioxide produced from different operations of the product life cycle from initial stage of extraction to final stage of disposal including usage and production phase [9]. There are different methodologies used to calculate CFP [10]. The recently developed ISO/TS 14067 [11] supports specific standards and requirements for the calculation and communication of the CFP of products, based on ISO standards $[12,13]$ and CFP labels [14]. The GHG protocol product standard was published in 2011 by the World Resources Institute (WRI) and World Business Council for Sustainable Development (WBCSD), to provides procedures for measuring the GHG records of products [15]. The Publicly Available Specifications (PAS) 2050, developed by the British Standard Institution, on ISO 14040 and 14044 standards for life cycle assessment of product [12,13]. A climate declaration developed by Environmental Product Declaration (EPD), to study the GHG emissions [16]. GHG emissions can be categorized into three scopes to support organizations for emissions control and management. Scope 1 includes those emissions, which are directly derived from sources managed by host organization. In contrast, scope 2 is indirect GHG emissions from the consumption of purchased electricity or steam generation and scope 3 emissions are related to the consequences of operations of organization, but not directly owned by the organizations e.g., logistics, business travel, and several more [17]. This paper considers all three scopes of GHG emission for analysis.

Sustainable machining is a branch of sustainable manufacturing, which deals to improve environmental conditions, reduces cost of machining, and waste and power consumption. Sustainable machining introduced dry machining, near dry machining and cryogenic machining [18]. During the usage phase, Metal Working Fluids (MWFs) can be easily contaminated by microorganisms, and cause health problems for workers due to inhalation of bio-aerosols [19]. On the other hand, Minimum Quantity Lubrication (MQL) is sustainable at process level, and reduces the real cause of heat i.e., friction between cutting tool and work part to improve the tool life and ultimately results in high production rate [20,21]. MQL consists of compressed air with small amount of oil to avoid large volume of waste as in conventional MWFs [22]. To address the need to minimize the use of harmful and expensive cutting fluid, researchers started working to investigate use of MQL at the process level [19]. It is estimated that by using MQL in cutting operations, the cutting temperature can be reduced by $5-10 \%$ [23]. In addition, the tool life can be increased by four times with the use of MQL as compared to dry cutting machining [24]. Two scenarios of machining operations using MQL and conventional MWF are presented in Figure 1. This paper deals with multiobjective Genetic Algorithm (GA) and goal attainment techniques to obtain optimal minimum solutions in terms of total cost of production and carbon emission by considering sustainable technologies. Total cost includes manufacturing cost, crashing cost, holding cost, warehousing cost, reworking, MQL, and scrap cost. Carbon emissions can be calculated from the manufacturing processes of industry, which consumed energy resources i.e., electricity, diesel, and gasoline.

The paper is designed as follows: Section 2 represents the reviews of researchers about sustainability, carbon footprint, and MQL. In this way, Section 3 develops the mathematical model with the help of assumptions and formulation. Solution methodology of the mathematical model is given in Section 4, where brief attributes of GA and goal attainment techniques are revised. Sections 5 and 6 depict the numerical example and results respectively, to show the pragmatic application of proposed mathematical model. Section 7 contains the sensitivity analysis to illustrate how much the model is sensitive along adjustments of different parameters. Finally, Section 8 concludes the research work of this paper. 

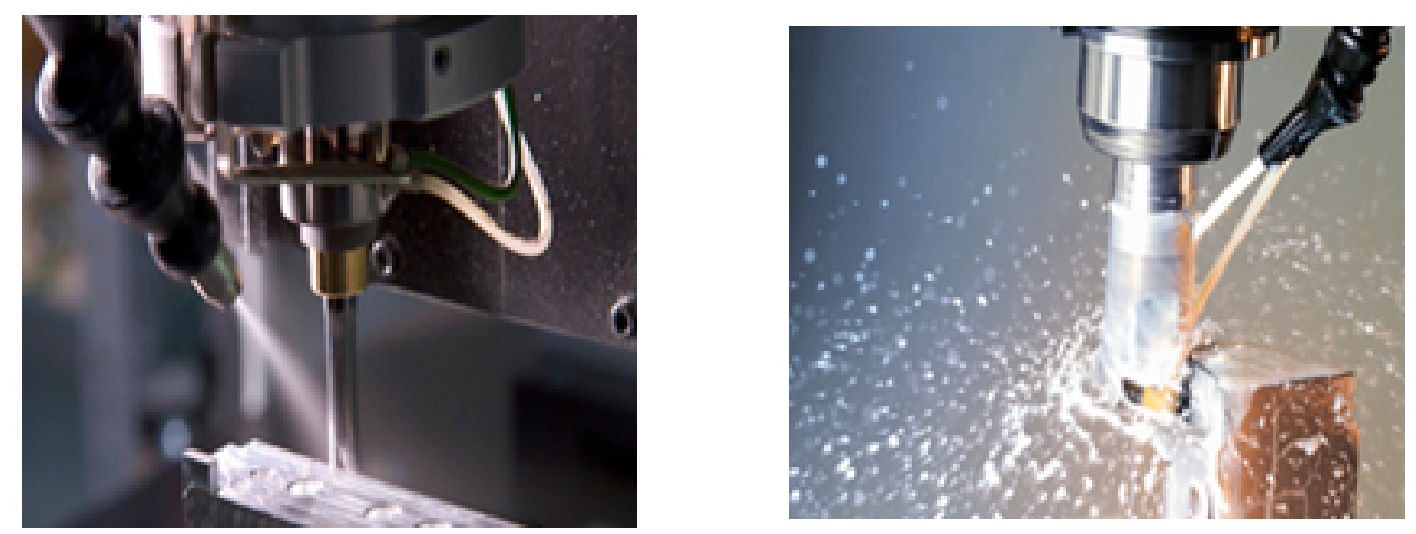

Figure 1. Cutting operation with metalworking fluids. A view of minimum quantity lubrication, sprayed with the help of nozzle (left). A view of conventional metalworking fluid, used as coolant ( right).

\section{Literature Review}

Sustainable manufacturing is taken as an important part of sustainable supply chain and represented as emergent technologies to produce finished products from raw material by consumption of energy, GHG emissions, generation of waste, and use of materials [25]. Wang and Li [26] developed a technique, based on demand of electricity including production restriction to enhance efficiency of energy and cost-effectiveness in manufacturing systems. Rosen and Kishawy [27] represented the way to integrate the principals of sustainability with design and manufacturing along with significant objectives i.e., profit, competitiveness, and production rate. During last decade, it has been an important aspect of organizations to consider sustainability in policy making and strategic decisions to meet the demand of customers beyond financial measures [28].

Many progressive companies, such as Walmart, Tesco, Hewlett Packard, and Patagonia, have capitalized on the opportunities of green supply chain management and are therefore very concerned with the environmental burden of their supply chain processes. Throughout the supply chain, designing and operating supply chains are particularly sensitive to reduce carbon emissions [29]. For minimizing carbon emissions, Kannan [30] develop a mixed integer programming model related to cost of production, network design for reverse logistics, and distribution. Manufacturing firms must consider profitability ratios, to focus clearly on reducing carbon emission by enhancing operational systems [31]. It is an urgent solution to the world's global warming issue that products are being given CFP labels to reduce carbon emission [32]. Wang et al. [33] devised CFP labelling system by summarizing data regarding electricity consumption, and equivalent carbon emissions associated with the manufacturing of products. This paper also considers the CFP calculation approach of Wang et al. [33] and deals with all three scopes of GHG emissions.

At the process level, the manufacturing industry is searching for a way to minimize the use of cutting fluid; coolant used in machine tools for manufacturing process is thought to be unsuitable due to economic, health, and environmental issues [34]. Koné et al. [35] reported that coolant management costs comprise $7.5 \%$ to $17 \%$ of the total manufacturing cost, which is more as compared to $4 \%$ for cutting tools. It is estimated that manufacturers use over 2 billion liters of MWFs each year, producing a substantial demand of non-renewable feedstock [36]. A method was developed to reduce the usage of MWFs using end mill in high-speed milling operation [37]. Fratila [38] and Fratila and Caizar [39] proposed an application of MQL in gear milling operations to provide quality and for the safety of the worker.

To meet the direction and requirements of lean and sustainable manufacturing, management of scraps and reworks are an important issue for manufacturing systems [40,41]. Inderfurth et al. [42] proposed an inventory model to ensure that the defective items also produced commonly in same 
production facility. Various researchers worked on imperfect production system to reflect the real scenario of industry (See: [43-46]). From the solution methodology perspective, Minjung developed a mixed integer linear programming (MILP) model to optimize the remanufacturing plan to justify justify the economic and environmental benefits of a product [47]. Masoud and Saeed used GA in fuzzy environment to balance the assembly line of automobile production line [48]. Wang et al. [33] developed a monitoring system for data collection of manufacturing process, by proposing a fuzzy multiple goal model to minimize total cost of production and carbon emissions to develop an integrated system to supports CFP label. In addition, the goal attainment technique was used to obtain the optimal solution of fuzzy multiple goal with a variation of production quantity. The research contributions regarding cost minimization, carbon emissions, MQL and imperfect production are given in Table 1. Researchers worked on the analysis of how MQL improves the cutting operations in terms of tool life, surface finish, and quality of cutting part. Still there is a research gap to study the effect of MQL on the production system by considering cost of MQL. Considering imperfect products in given model, it can be more realistic for practical application. It is also assumed that the inspected scrap can be disposed in a sustainable way. This paper extends the model of Wang et al. [33] to calculate the minimum total cost of production and carbon emissions by adding MQL lubrication in manufacturing system to assure sustainable machining is a step towards sustainability.

Table 1. Authors contribution table.

\begin{tabular}{ccccc}
\hline Authors & Costs & Sustainability Factors & Imperfect Items & Techniques \\
\hline $\begin{array}{c}\text { Inderfurth et al. } \\
(2005)\end{array}$ & $\begin{array}{c}\text { Cost of } \\
\text { rework }\end{array}$ & & $\begin{array}{c}\text { Rework and product } \\
\text { deterioration }\end{array}$ & $\begin{array}{c}\text { Lot sizing } \\
\text { formulas }\end{array}$ \\
\hline $\begin{array}{c}\text { Biswas and } \\
\text { Sarkar (2008) }\end{array}$ & Total cost & $\mathrm{CO}_{2}$ & $\begin{array}{c}\text { Experimental } \\
\text { design }\end{array}$ \\
\hline $\begin{array}{c}\text { Kannan } \\
(2012)\end{array}$ & $\begin{array}{c}\text { Cost of } \\
\text { emissions }\end{array}$ & $\mathrm{CO}_{2}$ & Rework & $\begin{array}{c}\text { Mixed integer } \\
\text { linear modelling }\end{array}$ \\
\hline $\begin{array}{c}\text { Tayyab and } \\
\text { Sarkar (2016) }\end{array}$ & $\begin{array}{c}\text { Cost of } \\
\text { production }\end{array}$ & & $\begin{array}{c}\text { Analytical } \\
\text { Optimization }\end{array}$ \\
\hline $\begin{array}{c}\text { Wang et al. } \\
(2016)\end{array}$ & $\begin{array}{c}\text { Total cost } \\
\text { of production } \\
\text { Total cost } \\
\text { of production }\end{array}$ & $\begin{array}{c}\mathrm{CO}_{2} \text { emissions } \\
\text { and MQL }\end{array}$ & $\begin{array}{c}\text { Rework and } \\
\text { scrap }\end{array}$ & $\begin{array}{c}\text { Fuzzy multiobjective } \\
\text { goal programming }\end{array}$ \\
\hline This paper & $\begin{array}{c}\text { Goal attainment and } \\
\text { multiobjective GA }\end{array}$ \\
\hline
\end{tabular}

\section{Mathematical Model}

The proposed model integrates multiobjective and multiconstraint, considering the manufacturing phase of automobile part industry, which manufacture automobile parts i.e., $\mathrm{X}, \mathrm{Y}$ and $\mathrm{Z}$. These automobile parts are manufactured through a well-designed manufacturing processes i.e., sealing tube, pipe bending, stuffing, stamping, cutting, chemical cleaning, welding, rivets and packaging. The production flow diagram of automobile parts is given as in Figure 2 [33]. Cutting operation of the production flow is under consideration, where material working fluid is used to reduce the heat produced between tool and part. This model proposes replacing of cutting fluid by MQL at cutting operation of manufacturing process to improve environmental, societal and economic fronts. Due to limitations of operational cost, due dates and resources, the manufacturing firm outsourced laser and coating operations. For selecting outsourcers, the industry must consider data of cost, quality, and carbon emissions restrictions. 


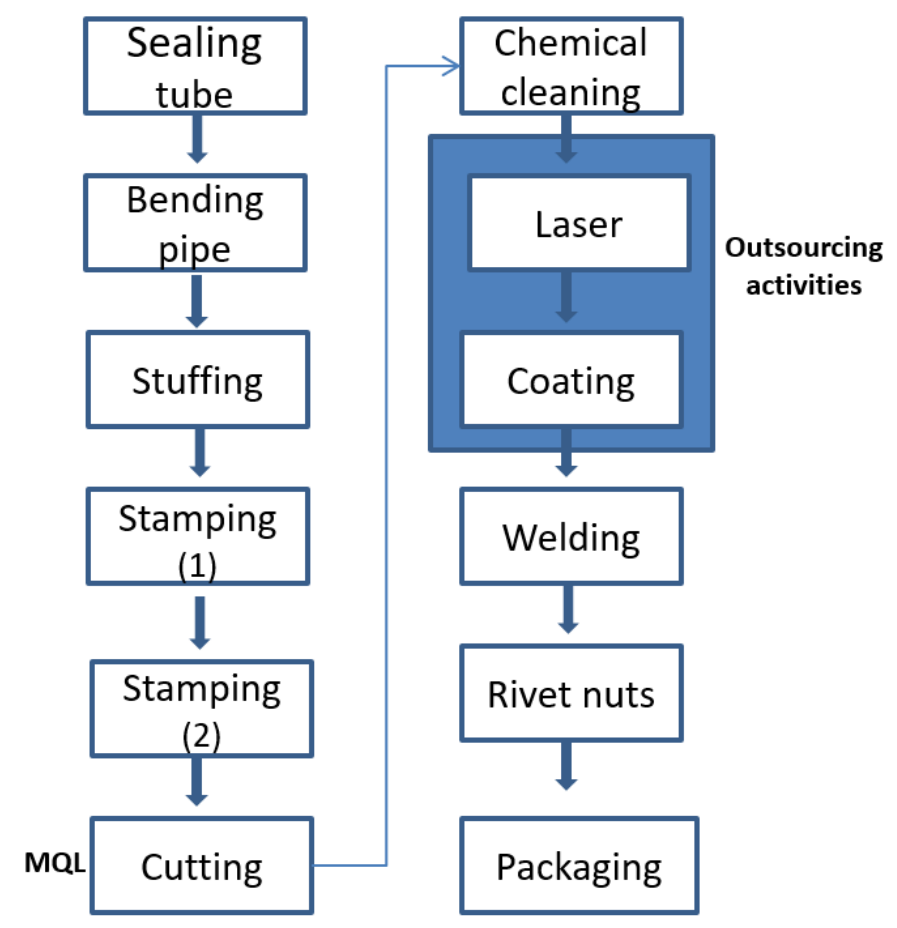

Figure 2. Production flow of automobile part industry.

\subsection{Assumptions}

Following assumptions are considered while developing the model.

1. This model considers an economic production quantity (EPQ) for multi type product with known demand and constant production rate, where the production rate is greater than demand rate such that there are no shortages in the model.

2. Cost of production includes labor costs and energy costs, where energy sources include electricity, diesel, and gasoline. Other sources of carbon emission are neglected. Two processes of production flow i.e., laser and coating operations are outsourced. Furthermore, in house and outsourced manufacturing facilities have limited capacity.

3. Vendors must satisfy quality and environmental laws.

4. It is assumed that imperfect production can be reworked, but certain proportion in form of scrap are produced after quality inspection. Those items are sale out by scrap price.

5. Carbon emissions and cost of MQL are considered. However, the cost of MQL is not included in the manufacturing cost.

\subsection{Notation}

The input parameters and decision variables for production, outsourcing, and vendors are enlisted comprehensively as in Appendix A.

\subsection{Model Formulation}

The proposed model is based on EPQ model. Total time period of automobile production system is $T$. Initially, production of automobile parts starts at time $t=0$, and continues to reach maximum level of inventory with in time $t_{1}$ while parts are also being delivered to the retailer at rate of demand $(-D)$. At time $t_{1}$, production stops but finished parts are still transported to the retailer until inventory reaches to zero. An optimal quantity is calculated, and the manufacturer or buyer should order for multi type product by balancing the average holding cost and ordering cost. This multi objective 
optimization model based on EPQ is formulated to minimize the production cost as a first objective and carbon emissions as a second objective. Total cost of production includes fixed cost, manufacturing cost and crashing cost, holding cost, maintenance cost, warehousing cost, energy cost, rework with scrap, and cost of MQL. Chalmers [49] stated that each year, more than 100 million gallons of MWFs are used in the U.S. and almost 1.2 million employees are unprotected by health hazards produced by it. An additional cost is incurred for recycling of wet chip produced by application of conventional cutting fluid. On the other hand, MQL produces dry chips, thus the cost of drying process in terms of time and process is reduced. The savings in cutting fluid and related costs becomes significant by considering MQL in this model as a separate cost to show its importance. However, few authors believe that MQL is not economical as compared to conventional metal working fluids. This research is mainly focusing on the positive environmental impact of MQL system to attend sustainable machining. Therefore, MQL should be adopted in machining even to compromise its high cost (if 2nd case), a step towards sustainability. In addition, the imperfect production is profoundly inspected to sort out the scrap, which can be eliminated from the line and are salvaged. Let $\beta$ be the proportion of imperfect production and $\alpha \beta$ be the proportion of scrap declared by inspection process. Now $\beta-\alpha \beta$ is proportion of the parts added in the production line after rework. Hence, total cost in terms of production quantity can be given as

$$
\begin{aligned}
\text { Minimize } z_{1} & =\text { Fixed cost }+ \text { Manufacturing cost }+ \text { Crashing cost }+ \text { Holding cost }+ \text { Maintenance cost } \\
& + \text { Warehouse cost }+ \text { Electricity cost }+ \text { Cost of diesel } \\
& + \text { Cost of gasoline }+ \text { Reworking cost }+ \text { Outsourcing cost }+ \text { Cost of MQL system } \\
& + \text { Scrap cost }
\end{aligned}
$$

The first aim of this model is to reduce the total cost of the system. The industry needs to check each cost carefully to verify, which cost consumes the major part of the total cost. Therefore each cost is required to be calculated separately given as in Equations (1)-(13).

\section{Fixed Cost (FC)}

This cost is an independent of the production quantity. It is time related, which consists of initial investment and setup cost of production as given in Equation (1).

$$
\mathrm{FC}=\sum_{j=1}^{J} \sum_{t=1}^{T}\left(F C_{j t}\right)
$$

Manufacturing Cost (MC)

It is the sum of all costs incurred in the resources required to make products. It is related to the manufacturing operations of product considering in-house production and it covers labor costs and processing costs expressed in the form of Equation (2).

$$
\mathrm{MC}=\sum_{j=1}^{J} \sum_{t=1}^{T}\left(M C_{j t} \times M Q_{j t}\right)
$$

Crashing Cost (CC)

Crashing cost is used to improve service level for customers by controlling extra resource in terms of labor, machine, and energy utilization. It depends upon the quantity to crash the production as given in Equation (3)

$$
\mathrm{CC}=\sum_{j=1}^{J} \sum_{t=1}^{T}\left(C C_{j t} \times C Q_{j t}\right)
$$




\section{Holding Cost (HC)}

It is referred to the cost of carrying inventory in the production house for this model. The holding cost of production model will be incurred on production and crashing quantity, which includes costs such as rent, salaries, and insurance. It depends upon how much time the final product will be holding in inventory and can be expressed as in Equation (4).

$$
\mathrm{HC}=\sum_{j=1}^{J} \sum_{t=1}^{T} H C_{j t} \times\left(M Q_{j t}+C Q_{j t}\right)
$$

Maintenance cost (mC)

The main objective of maintenance is to mitigate results of failure of equipments and improve their service levels. It includes lubricants, oils, spare parts, and maintenance kits. It can be calculated as in Equation (5).

$$
\mathrm{mC}=\sum_{j=1}^{J} \sum_{t=1}^{T} m C_{j t}
$$

Warehousing Cost (WC)

These costs cover costs associated with the activities of warehouse inventory except holding cost. It includes cost of inventory in warehouse to control and maintain i.e., rent, utilities, salaries and insurance of warehouse. It can be calculated as in Equation (6)

$$
\mathrm{WC}=\sum_{j=1}^{J} \sum_{t=1}^{T} W C_{j} \times\left(M Q_{j t}+C Q_{j t}\right)
$$

\section{Energy Cost (EC)}

Energy cost covers several costs due to consumption of electricity (ECC), gasoline (GC), and diesel (DC) in manufacturing, rework, and outsourcing processes. The main source of energy used for production is electricity, whereas diesel and gasoline are used as an auxiliary source to fulfill the demand. These costs are represented in form of Equations (7)-(9).

$$
\begin{gathered}
\mathrm{ECC}=\sum_{j=1}^{J} \sum_{t=1}^{T} \gamma_{1} E P_{j}\left(M Q_{j t}+C Q_{j t}\right)+\sum_{j=1}^{J} \sum_{t=1}^{T} \gamma_{1} E R_{j} O Q_{i j t}\left(1-\alpha_{i j t}\right) \beta_{i j t} \\
\mathrm{DC}=\sum_{j=1}^{J} \sum_{t=1}^{T} \gamma_{2} D P_{j}\left(M Q_{j t}+C Q_{j t}\right)+\sum_{j=1}^{J} \sum_{t=1}^{T} \gamma_{2} D R_{j} O Q_{i j t}\left(1-\alpha_{i j t}\right) \beta_{i j t} \\
\mathrm{GC}=\sum_{j=1}^{J} \sum_{t=1}^{T} \gamma_{3} G P_{j}\left(M Q_{j t}+C Q_{j t}\right)+\sum_{i=1}^{I} \sum_{j=1}^{J} \sum_{t=1}^{T} \gamma_{3} G R_{j} O Q_{i j t}\left(1-\alpha_{i j t}\right) \beta_{i j t}
\end{gathered}
$$

\section{Outsourcing Cost (OC)}

Due to limitation of resources, outsourcing cost is incurred for laser and coating operations, which are operated by three vendors: A, B, and C as given in Equation (10) [50].

$$
\mathrm{OC}=\sum_{i=1}^{I} \sum_{j=1}^{J} \sum_{t=1}^{T} O C_{i j t} \times O Q_{i j t}
$$




\section{Reworking Cost (RC)}

Inspection stations are installed after laser and coating operations to check the defective parts along the manufacturing line. Those rework parts again backtracked on same machines for processing, carry costs of operation, labor and energy, which are called reworking cost as given in Equation (11).

$$
\mathrm{RC}=\sum_{i=1}^{I} \sum_{j=1}^{J} \sum_{t=1}^{T} V C_{i j t} \times O Q_{i j t} \times\left(1-\alpha_{i j t}\right) \times \beta i j t
$$

Cost of MQL (MQLC) and Scrap (SC)

MQL system consists of installation, MQL lube, and maintenance cost, while scrap cost is due to the defective items sold by discounted price. Cost of MQL and scrap are given as in Equations (12) and (13).

$$
\begin{gathered}
\mathrm{MQLC}=\sum_{i=1}^{I} \sum_{j=1}^{J} M Q L_{j t} \times\left(M Q_{j t}+C Q_{j t}\right) \\
\mathrm{SC}=\sum_{i=1}^{I} \sum_{j=1}^{J} \sum_{t=1}^{T} S_{j} \times O Q_{i j t} \times \alpha_{i j t} \times \beta_{i j t}
\end{gathered}
$$

From the costs given in Equations (1)-(13), overall production cost can be expressed in the form of Equation (14)

$$
\begin{aligned}
\operatorname{Min} z_{1} & =\sum_{j=1}^{J} \sum_{t=1}^{T}\left(F C_{j t}+M C_{j t} \cdot M Q_{j t}+C C_{j t} C Q_{j t}\right)+\sum_{j=1}^{J} \sum_{t=1}^{T} H C_{j t}\left(M Q_{j t}+C Q_{j t}\right)+\sum_{j=1}^{J} \sum_{t=1}^{T} m C_{j t} \\
& +\sum_{j=1}^{J} \sum_{t=1}^{T} W C_{j}\left(M Q_{j t}+C Q_{j t}\right)+\sum_{j=1}^{J} \sum_{t=1}^{T} \gamma_{1} E P_{j}\left(M Q_{j t}+C Q_{j t}\right) \\
& +\sum_{i=1}^{I} \sum_{j=1}^{J} \sum_{t=1}^{T} \gamma_{1} E R_{j} O Q_{i j t}\left(1-\alpha_{i j t}\right) \beta_{i j t} \\
& +\sum_{j=1}^{J} \sum_{t=1}^{T} \gamma_{2} D P_{j}\left(M Q_{j t}+C Q_{j t}\right)+\sum_{i=1}^{I} \sum_{j=1}^{J} \sum_{t=1}^{T} \gamma_{2} D R_{j} O Q_{i j t}\left(1-\alpha_{i j t}\right) \beta_{i j t} \\
& +\sum_{j=1}^{J} \sum_{t=1}^{T} \gamma_{3} G P_{j}\left(M Q_{j t}+C Q_{j t}\right)+\sum_{i=1}^{I} \sum_{j=1}^{J} \sum_{t=1}^{T} \gamma_{3} G R_{j} O Q_{i j t}\left(1-\alpha_{i j t}\right) \beta_{i j t} \\
& +\sum_{i=1}^{I} \sum_{j=1}^{J} \sum_{t=1}^{T} V C_{i j t} O Q_{i j t}\left(1-\alpha_{i j t}\right) \cdot \beta i j t+\sum_{i=1}^{I} \sum_{j=1}^{J} \sum_{t=1}^{T} O C_{i j t} O Q_{i j t} \\
& +\sum_{i=1}^{I} \sum_{j=1}^{J} M Q L_{j t}\left(M Q_{j t}+C Q_{j t}\right)+\sum_{i=1}^{I} \sum_{j=1}^{J} \sum_{t=1}^{T} S_{j} O Q_{i j t} \alpha_{i j t} \beta_{i j t}
\end{aligned}
$$

The second objective of the model is to minimize the carbon emissions from production operations. carbon emissions are the total carbon emissions from in-house, outsourced, and reworking manufacturing, which depend on sources of energy used i.e., electricity, gasoline, and diesel as given as

$$
\begin{aligned}
\text { Minimize } z_{2}= & \text { Carbon emissions due to electricity in manufacturing, outsourcing and reworking operations } \\
+ & \text { Carbon emissions due to burning of diesel in manufacturing, outsourcing and } \\
& \text { reworking operations + Carbon emissions due to burning of gasoline }
\end{aligned}
$$


The above equation represents the theocratical form to minimize the carbon emissions. Carbon produced from in-house manufacturing is the sum of emissions due to electricity, diesel, and gasoline utilized at in-house production system. A portion of carbon emissions results due to outsourcing operation of laser and coating operation. Small portion of carbon emissions is also produced by reworking operations. In the proposed model, it is considered that a proportion of imperfect production move to the scrap stock cannot be reworked and are sold out by discounted rate to be disposed in sustainable way. This small portion of scrap due to not reworking will also reduce the carbon emissions to some extent by not manufacturing $O Q_{i j t} \times \beta_{i j t} \times \alpha_{i j t}$. To express mathematically, the total carbon emissions produced from system by in-house manufacturing, outsourcing and reworking can be given mathematically as given in Equation (15).

$$
\begin{aligned}
\operatorname{Min} z_{2} & =\sum_{j=1}^{J} \sum_{t=1}^{T}\left(\alpha_{1} E P_{j}+\alpha_{2} D P_{j}+\alpha_{3} G P_{j}\right) \times\left(M Q_{j t}+C Q_{j t}\right) \\
& +\sum_{i=1}^{I} \sum_{j=1}^{J} \sum_{t=1}^{T}\left(\alpha_{1} E O_{i j}+\alpha_{2} D O_{i j}+\alpha_{3} G O_{i j}\right) \times O Q_{i j t} \\
& +\sum_{i=1}^{I} \sum_{j=1}^{J} \sum_{t=1}^{T}\left(\alpha_{1} E R_{j}+\alpha_{2} D R_{j}+\alpha_{3} G R_{j}\right) \times O Q_{i j t} \beta_{i j t} \times\left(1-\alpha_{i j t}\right)
\end{aligned}
$$

\subsection{Constraints}

The production system has given some limitations for production, outsourcing and reworking quantity. These constraints are related to demand, order quantity, manufacturing capacity, and vendor capacity, which are given as from Equations (16)-(23).

Demand Limitation

$$
\sum_{j=1}^{J} \sum_{t=1}^{T}\left(M Q_{j t}+C Q_{j t}\right) \cong D_{j}
$$

Order Quantity

$$
\sum_{j=1}^{J} \sum_{t=1}^{T}\left(M Q_{j t}+C Q_{j t}\right)=\sum_{i=1}^{I} \sum_{j=1}^{J} \sum_{t=1}^{T} O Q_{i j t}
$$

Manufacturing Capacity

$$
\begin{aligned}
& M Q_{j t} \leq M L_{j t} \\
& M Q_{j t} \geq M U_{j t}
\end{aligned}
$$

Vendor Capacity

$$
\begin{aligned}
& O Q_{i j t} \leq A S_{i j t} \\
& O Q_{i j t} \geq B S_{i j t}
\end{aligned}
$$

Crashing Quantity Limitation

$$
\sum_{j=1}^{J} \sum_{t=1}^{T} C Q_{j t} \times C C_{j t} \leq N T_{j t}
$$

Non Negativity Constraints

$$
M Q_{j t}, C Q_{j t}, O Q_{i j t} \geq 0
$$


Some constraints are not expressed in mathematical form, but applied to vendors A, B, and C to control the emissions of carbon and quality of product during production to maintain quality and environmental laws. Now, the model is solved to minimize the total cost of the system subject to above-mentioned constraints.

\section{Solution Methodology}

Today's alarming situation of world global warming and increasing awareness among customers has increased the demand for sustainable products, which creates competition in international markets. For this reason, manufacturers are compelled to provide life cycle sustainability at products, processes, and system levels. A mathematical model representing machine based automobile part industry is taken under consideration for analysis. Economic and environmental factors of sustainability are promised to consider in the form of two objectives by minimizing total cost of production and carbon emission, respectively. A sustainable technology, i.e., MQL system, is replaced with the conventional metal working fluid in cutting operation of process flow and scrap management is also done to make model more practical. The system of equations generated from the formulation of model are complex to get a feasible solution for multiobjective, with multiple items, and constraints by using any analytical approach. Different techniques can be used to find the optimal solution of multiobjective mathematical model in form of systems of equations. GA is a population based algorithm, uses two operators of mutation and cross over, and is suited well for multiobjective problems. It is the property of GA to search simultaneously different regions and find diverse set of solutions for complex problems with multiobjective and multimodal solutions spaces. In addition, it does not require the user to prioritize, scale, or weight the objectives [51]. The components of GA are fitness functions, diversity, elitisim, constraints handling and hybrid multiobjective GA. A fitness function is an objective function that is used to represent a given design solution to achieve set objective [52]. Diverse set of population is a significant characteristic of multiobjective GA to get uniformly distributed solutions over pareto front. Elitism means that the fittest solution found till now during searching always survives to the next generation. Constraint handling is an important feature of GA. Most real world problems include constraints, which are satisfied well by multiobjective GA. Hybrid multiobjective GA methodology is used to find the optimal solution in less performance time. For this research work, multiobjective methodology is used to obtain near optimal solution comparing to other methods by using stochastic uniform selection function. A forward migration strategy and scattered function for crossover are selected for the solution. Furthermore, the elite count is considered as 2 while crossover fraction is 0.8. In addition, the model is restricted by several constraints. On the other hand, the goal-attainment method is an intelligent tool to obtain the best-compromising solution and it is not subject to the limitation of convexity [53]. Goal attainment is an approach used to solve multiobjective programming, consisting of vectors of weights $w_{1}, w_{2}, w_{3}, \ldots, w_{n}$ related to the goals vector $v_{1}, v_{2}, v_{3} \ldots, v_{n}$ for the objective functions $f_{1}, f_{2}, f_{3} \ldots, f_{n}$. This technique informs decision makers that whether the desired goal is attainable or an improved solution will be attained. These are the some reasons that GA and goal attainment are evaluated as the best techniques for simultaneous optimization of multiobjective with minimum computational time. This paper deals with a mathematical model based on economic production quantity (EPQ) model with multiobjective linear programming by considering the production phase of an automobile part industry. Automobile parts i.e., parts X, Y, and $\mathrm{Z}$ are produced in-house through manufacturing processes i.e., sealing, bending, stuffing, stamping, cutting, cleaning, laser, coating, welding, fastening and packaging. Due to less capacity of resources and operation costs, the industry outsourced laser and coating operations to three vendors A, B, and C. Source of energy required for manufacturing processes are electricity, diesel, and gasoline. The carbon footprint can be calculated by adding carbon emissions from in-house manufacturing, outsourcing, and reworking operations. Carbon footprints are summed over manufacturing procedures and then 
converted into equivalent carbon emissions with the help of conversion factor. There is a standard formula for conversion of energy consumption of particular sources to carbon emission, given as

$$
\text { Carbon footprint }=\text { Energy consumption } \times \text { Carbon emission conversion factor }
$$

\section{Numerical Example}

Data is collected from the research work done by Wang et al. [33] except the data regarding MQL system, and scrap. Many parametric values are based upon historical statistic data. Manufacturing operational data is obtained by electricity monitoring system, integrated with the network system. Electricity consumption data is collected from electric meters and data of diesel and gasoline consumed are measured from past reports. Outsourcing data is collected from concerned contracted vendors. Table 2 shows the data regarding total cost of production for items $X, Y$, and $Z$ and two periods 1 and 2 . Major costs are fixed cost, manufacturing, crashing, holding, maintenance cost, and warehousing cost.

Table 2. Manufacturing cost data (US\$).

\begin{tabular}{ccccccccc}
\hline Period & $\begin{array}{c}\text { Product } \\
\text { Type }\end{array}$ & $\begin{array}{c}\text { Fixed } \\
\text { Cost }\end{array}$ & $\begin{array}{c}\text { Manufacturing } \\
\text { Cost/Unit }\end{array}$ & $\begin{array}{c}\text { Crashing } \\
\text { Cost/Unit }\end{array}$ & $\begin{array}{c}\text { Holding } \\
\text { Cost/Unit }\end{array}$ & $\begin{array}{c}\text { Maintenance } \\
\text { Cost }\end{array}$ & $\begin{array}{c}\text { MQL } \\
\text { Cost/Unit }\end{array}$ & $\begin{array}{c}\text { Warehousing } \\
\text { Cost/Unit }\end{array}$ \\
\hline 1 & $\mathrm{X}$ & 2307 & 0.32 & 0.42 & 0.25 & 510.5 & 0.0725 & 0.067 \\
2 & $\mathrm{Y}$ & 2307 & 0.29 & 0.39 & 0.21 & 255.26 & 0.0725 & 0.08 \\
& $\mathrm{Z}$ & 2780 & 0.18 & 0.23 & 0.04 & 574.33 & 0.0725 & 0.13 \\
\hline
\end{tabular}

Table 3 depicts cost of reworking, scrap and MQL. Cost of MQL is assumed as $m \%$ of manufacturing cost for $\mathrm{X}, \mathrm{Y}$, and $\mathrm{Z}$ item, respectively. Based on Koné et al. [35] report, the coolant management costs comprise $7.5 \%$ to $17 \%$ of the total manufacturing cost, thus $m$ is considered as the average of 7.5 and 17 i.e., $12.25 \%$ of manufacturing cost. Scrap cost for each item is considered as $\$ 0.083$ for each item.

Table 3. Cost data related to reworking (US\$).

\begin{tabular}{cccc}
\hline Period & Product Type & Rework Cost/Unit & Scrap Cost/Unit \\
\hline 1 & $\mathrm{X}$ & 0.116 & 0.083 \\
2 & $\mathrm{Y}$ & 0.116 & 0.083 \\
& $\mathrm{Z}$ & 0.15 & 0.083 \\
\hline
\end{tabular}

Energy cost includes cost incurred by the usage of electricity, diesel, and gasoline for production of automobile parts with the coefficients of carbon dioxide equivalent to each source are given in Table 4 . Table 5 shows limitations of production quantity and crashing quantity in terms of capacity units.

Table 4. Energy cost and carbon emissions.

\begin{tabular}{ccc}
\hline Energy Source Type & Unit Cost (\$) & Carbon Emissions Conversion Factor \\
\hline Electricity $(\mathrm{kWh})$ & 0.1 & 0.536 \\
Diesel fuel $(\mathrm{L})$ & 1.06 & 2.615 \\
Gasoline $\left(\mathrm{m}^{3}\right)$ & 0.6 & 1.881 \\
\hline
\end{tabular}

Table 5. Manufacturing capacity with limitations.

\begin{tabular}{ccccc}
\hline Period & Product Type & Upper Capacity (Units) & Lower Capacity (Units) & Crashing Quantity Limit (Units) \\
\hline 1 & X & 570 & 80 & 250 \\
2 & Y & 290 & 80 & 125 \\
& Z & 345 & 70 & 75 \\
\hline
\end{tabular}


Table 6 presents the data regarding energy consumption by mean of electricity, diesel, and gasoline in manufacturing processes, rework, and outsourcing. Outsourcing data is given in Table 7. It is assumed that there are three vendors i.e., $\mathrm{A}, \mathrm{B}$, and $\mathrm{C}$ working on outsourcing activities for laser and coating operations. Outsourcing data includes capacity limit of vendors, cost, defective percentage, and scrap percentage.

Table 6. Energy consumption data.

\begin{tabular}{ccccc}
\hline Status & Product Type & Electricity (kWh) & Diesel Fuel (L) & Gasoline $\mathbf{( m}^{3} \mathbf{)}$ \\
\hline Manufacturing & $\mathrm{X}$ & 0.318 & 0.3184 & 0.0004 \\
Manufacturing & $\mathrm{Y}$ & 0.293 & 0.0937 & 0.0005 \\
Manufacturing & $\mathrm{Z}$ & 0.455 & 0.0005 & 0.0005 \\
Reworking & $\mathrm{X}$ & 0.675 & 0.0055 & 0 \\
Reworking & $\mathrm{Y}$ & 0.702 & 0.0055 & 0 \\
Reworking & $\mathrm{Z}$ & 0.757 & 0.011 & 0 \\
Outsourcing by A & $\mathrm{X}$ & 0.654 & 0.008 & 0 \\
& $\mathrm{Y}$ & 0.637 & 0.008 & 0 \\
Outsourcing by B & $\mathrm{Z}$ & 0.72 & 0.015 & 0 \\
& $\mathrm{X}$ & 0.723 & 0.007 & 0 \\
Outsourcing by C & $\mathrm{Y}$ & 0.678 & 0.007 & 0 \\
& $\mathrm{Z}$ & 0.741 & 0.015 & 0 \\
& $\mathrm{X}$ & 0.7 & 0.01 & 0 \\
& $\mathrm{Y}$ & 0.655 & 0.01 & 0 \\
\hline
\end{tabular}

Table 7. Outsourcing data.

\begin{tabular}{cccccccc}
\hline Period & Vendor & $\begin{array}{c}\text { Product } \\
\text { Type }\end{array}$ & $\begin{array}{c}\text { Minimum } \\
\text { Limit (Units) }\end{array}$ & $\begin{array}{c}\text { Maximum } \\
\text { Limit (Units) }\end{array}$ & $\begin{array}{c}\text { Outsourcing } \\
\text { Cost (US\$) }\end{array}$ & $\begin{array}{c}\text { Defective } \\
\text { Rate (\%) }\end{array}$ & $\begin{array}{c}\text { Scrap } \\
\text { (\%) }\end{array}$ \\
\hline 1 & A & X & 100 & 1000 & 0.666 & 1.35 & 1.2 \\
& B & X & 100 & 1500 & 0.666 & 1.45 & 1.2 \\
& C & X & 150 & 2000 & 0.666 & 1.25 & 1.2 \\
\hline 2 & A & Y & 50 & 1000 & 0.6 & 1.45 & 1.2 \\
& B & Y & 50 & 1200 & 0.6 & 1.55 & 1.2 \\
& C & Y & 100 & 1200 & 0.6 & 1.45 & 1.2 \\
& A & Z & 50 & 800 & 0.833 & 1.2 & 1.2 \\
& B & Z & 50 & 500 & 0.833 & 1.55 & 1.2 \\
& C & Z & 100 & 1000 & 0.833 & 1.3 & 1.2 \\
\hline
\end{tabular}

\section{Numerical Results}

The formulation was first coded in MATLAB-16a and by using multiobjective GA and goal attainment, calculated the optimal values of total cost and carbon emissions in optimization toolbox. The crossover operator of GA creates a new fittest solution in unexplored parts of Pareto front with respect of different objectives. That is the reason, most multiobjective GA do not require to prioritize or weight objectives. Therefore, GA have been used as the most popular heuristic approach to multiobjective design and optimization problems. The decision variables in the form of production quantity, crashing quantity, and outsourcing quantity are calculated in the form of production allocation policy as given in Table 8 . These results can help managers to allocate production into in-house, crashing, and outsourcing quantity. The optimal values of the objectives were first obtained by single objectives GA individually then the data was analyzed by using multiobjective GA to obtain solution i.e., total production cost is $\$ 9925.652$ and carbon emissions is $817.44 \mathrm{~kg}$ (used PC having specifications: Core I-3, 4 GB, $3.7 \mathrm{GHz}$ ). On the other hand, the goal attainment technique uses weights and target value of the objectives as an input to find the solution i.e., $\$ 9925.636$ and $817.44 \mathrm{~kg}$, respectively. Both total cost and carbon emissions as objectives are given equal weight i.e., 0.5 and 0.5 , respectively and 
results of single objective GA are considered as target values of objectives. The results obtained by using single objective GA, multiobjective GA, and goal attainment technique are given in Table 9 . As the system of equations are linear, that is why significant differences do not occur among results. However, results obtained by using goal attainment are better than other. Computational time has been calculated for each techniques used for analysis of data. Single objective GA took almost $70 \mathrm{~s}$ computational time and on the other hand due to simultaneous solution of objectives, multiobjective GA took only $40 \mathrm{~s}$. As the goal attainment technique uses target values from single objective, that is why its computational time will be more than $70 \mathrm{~s}$. Now there is a tradeoff between the optimal solution and computational time for managers to decide in production planing for the selection of techniques.

Table 8. Optimal solution obtained by using goal attainment technique.

\begin{tabular}{cccccc}
\hline Period & $\begin{array}{c}\text { Product } \\
\text { Type }\end{array}$ & $\begin{array}{c}\text { Manufacturing } \\
\text { Status }\end{array}$ & $\begin{array}{c}\text { Production } \\
\text { Quantity (Units) }\end{array}$ & $\begin{array}{c}\text { Crashing } \\
\text { Quantity (Units) }\end{array}$ & $\begin{array}{c}\text { Outsourcing } \\
\text { Quantity (Units) }\end{array}$ \\
\hline 1 & $\mathrm{X}$ & In-house & 215 & 135 & 100 \\
& & Vendor A & & & 150 \\
& Vendor B & & & 100 \\
\hline & Vendor C & & 60 & 50 \\
& & In-house & 140 & & 50 \\
& Vendor A & & & 100 \\
\hline & Vendor B & & 65 & 100 \\
& Vendor C & & & 50 \\
& Z & In-house & 135 & & 50 \\
\hline
\end{tabular}

Table 9. Minimum cost and carbon footprint obtained by using GA and goal attainment techniques.

\begin{tabular}{ccccccc}
\hline $\begin{array}{c}\text { Objective } \\
\text { Function }\end{array}$ & $\begin{array}{c}\text { Single } \\
\text { Objective GA }\end{array}$ & $\begin{array}{c}\text { Computational } \\
\text { Time (s) }\end{array}$ & $\begin{array}{c}\text { Multi- } \\
\text { Objective GA }\end{array}$ & $\begin{array}{c}\text { Computational } \\
\text { Time (Seconds) }\end{array}$ & $\begin{array}{c}\text { Goal } \\
\text { Attainment }\end{array}$ & $\begin{array}{c}\text { Computational } \\
\text { Time (s) }\end{array}$ \\
\hline$z_{1}(\mathrm{US} \$)$ & 9925.655 & 33.74 & 9925.652 & 40.67 & 9925.6364 & 0.0838 \\
$z_{2}(\mathrm{Kg})$ & 817.4454 & 38.56 & 817.44 & & 817.44 & \\
\hline
\end{tabular}

\section{Sensitivity Analysis}

The total cost of production and carbon emissions as an objective of proposed model are influenced by energy resources and crashing. To crash more quantities, it may use extra consumption of resources which will increase the total cost of production. Similarly, the source of energy can also affect the total cost of production and carbon emission. Therefore, additional tests are necessary to cover different scenarios. Sensitivity analysis of proposed model consider 10 cases to observe, how much the total cost of production and carbon emission are changing with respect of average diesel usage and crashing cost. The first five cases are related to the sensitivity of results based on the effect of average diesel consumed in automobile part industry as given in Table 10, while next 5 cases give the effect of crashing cost as given in Table 11. All these cases are adjusted at a rate of $+50,+25,-25$ and -50 , respectively from the initial value. A dramatically change is observed in carbon emissions $\left(z_{2}\right)$ due to the adjustments of diesel usage as in Cases 1 and 5 i.e., $\pm 24.60 \%$. It is recommended that energy utilization must be conserved to achieve sustainability and by increasing the usage of non-renewable energy sources will rise carbon emissions. That is the reason, use of renewable energy as a source of energy must be encouraged to reduce the impact of world global warming. In addition, little effect occurs on total cost of production $\left(z_{1}\right)$ with the adjustment of diesel usage. It is also revealed that increasing the cost of crashing causes minor changes in the total cost of production $\left(z_{1}\right)$ by only $0.46 \%$ and $-0.46 \%$ as in 
Cases 6 and 10 respectively. On the other hand, crashing cost have no effect on carbon emissions $\left(z_{2}\right)$ of production system.

Table 10. Effect of diesel usage on model ( $z_{1}$ is total production cost and $z_{2}$ is carbon emissions).

\begin{tabular}{|c|c|c|c|c|c|c|}
\hline Case & $\begin{array}{l}\text { Product } \\
\text { Type }\end{array}$ & $\begin{array}{l}\text { Average diesel } \\
\text { Cost (US\$/kWh) }\end{array}$ & $\begin{array}{c}\text { Adjustment } \\
(\%)\end{array}$ & Function & $\begin{array}{c}\text { Result } \\
\text { (US\$ and kg) }\end{array}$ & $\begin{array}{c}\% \text { Change } \\
(\%)\end{array}$ \\
\hline \multirow{3}{*}{1} & $X$ & 0.10467 & \multirow[t]{3}{*}{50} & $z_{1}$ & 10030 & 1.05 \\
\hline & $\mathrm{Y}$ & 0.03726 & & $z_{2}$ & 1018.6 & 24.61 \\
\hline & $\mathrm{Z}$ & 0.03834 & & & & \\
\hline \multirow{3}{*}{2} & $x$ & 0.087225 & \multirow[t]{3}{*}{25} & $z_{1}$ & 9964.3 & 0.39 \\
\hline & $\mathrm{Y}$ & 0.03105 & & $z_{2}$ & 917.9 & 12.29 \\
\hline & $\mathrm{Z}$ & 0.03195 & & & & \\
\hline \multirow{3}{*}{3} & $x$ & 0.06978 & \multirow[t]{3}{*}{ Initial values } & $z_{1}$ & 9925.65 & 0 \\
\hline & $\mathrm{Y}$ & 0.02484 & & $z_{2}$ & 817.44 & 0 \\
\hline & $\mathrm{Z}$ & 0.02556 & & & & \\
\hline \multirow{3}{*}{4} & $x$ & 0.052335 & \multirow[t]{3}{*}{-25} & $z_{1}$ & 9887.1 & -0.39 \\
\hline & Y & 0.01863 & & $z_{2}$ & 716.89 & -12.30 \\
\hline & $\mathrm{Z}$ & 0.01917 & & & & \\
\hline \multirow{3}{*}{5} & $x$ & 0.03489 & \multirow[t]{3}{*}{-50} & $z_{1}$ & 9848.6 & -0.78 \\
\hline & $\mathrm{Y}$ & 0.01242 & & $z_{2}$ & 616.33 & -24.60 \\
\hline & $\mathrm{Z}$ & 0.01278 & & & & \\
\hline
\end{tabular}

Table 11. Effect of crashing cost on model ( $z_{1}$ is total production cost and $z_{2}$ is carbon emissions).

\begin{tabular}{|c|c|c|c|c|c|c|}
\hline Case & $\begin{array}{c}\text { Product } \\
\text { Type }\end{array}$ & $\begin{array}{c}\text { Crashing } \\
\text { Cost (US\$/Unit) }\end{array}$ & $\begin{array}{c}\text { Adjustment } \\
(\%)\end{array}$ & Function & $\begin{array}{c}\text { Result } \\
\text { (US\$ and kg) }\end{array}$ & $\begin{array}{c}\% \text { Change } \\
(\%)\end{array}$ \\
\hline \multirow{3}{*}{6} & $x$ & 0.63 & \multirow[t]{3}{*}{50} & $z_{1}$ & 9971.5 & 0.46 \\
\hline & $\mathrm{Y}$ & 0.585 & & $z_{2}$ & 818.66 & 0.15 \\
\hline & Z & 0.345 & & & & \\
\hline \multirow{3}{*}{7} & $x$ & 0.525 & \multirow[t]{3}{*}{25} & $z_{1}$ & 9949.7 & 0.24 \\
\hline & $\mathrm{Y}$ & 0.4875 & & $z_{2}$ & 817.44 & 0 \\
\hline & $\mathrm{Z}$ & 0.2875 & & & & \\
\hline \multirow{3}{*}{8} & $x$ & 0.42 & \multirow[t]{3}{*}{ Initial values } & $z_{1}$ & 9925.65 & 0 \\
\hline & $\mathrm{Y}$ & 0.39 & & $z_{2}$ & 817.444 & 0 \\
\hline & $\mathrm{Z}$ & 0.23 & & & & \\
\hline \multirow{3}{*}{9} & $X$ & 0.315 & \multirow[t]{3}{*}{-25} & $z_{1}$ & 9901.7 & -0.24 \\
\hline & $\mathrm{Y}$ & 0.2925 & & $z_{2}$ & 817.44 & 0 \\
\hline & $\mathrm{Z}$ & 0.1725 & & & & \\
\hline \multirow{3}{*}{10} & $x$ & 0.21 & \multirow[t]{3}{*}{-50} & $z_{1}$ & 9877.7 & -0.48 \\
\hline & $\mathrm{Y}$ & 0.195 & & $z_{2}$ & 817.44 & 0 \\
\hline & Z & 0.115 & & & & \\
\hline
\end{tabular}

\section{Conclusions}

This paper dealt with the multiobjective optimization model to achieve minimum production cost and carbon emissions from manufacturing process to develop an optimal allocation policy for the benefit of production firm. The results obtained from the analysis of the proposed model in the autoparts industry are highly dependent upon crashing cost and utilization of energy resources. If more diesel is used to fulfill the requirement of energy for production as compared to electricity, more carbon emissions will be generated from the process and vice versa. Industrial operations mainly based upon machining and selection of MWFs having significant impact on machining due to less environmental effect. MQL is known to be the best MWF for sustainable machining. The significant 
contribution of this paper is the inclusion of MQL and imperfect production to make given model more realistic towards sustainability. Optimal quantity of production, outsourcing, and reworking after deduction of scrap make the given model more diverse to find the possible minimum carbon emission from production of automobile parts. Minimum production costs and carbon emissions by using the goal attainment technique from numerical example insured that the proposed model could be implemented in any manufacturing industry and it is essential for decision makers to attend sustainability in terms of minimum cost (economic) and minimum carbon emissions (environmental) with addition of MQL and imperfect production (sustainable product).

In future, the model will be extended to obtain better results than this model by using other analytical techniques and methods. Production quantity may be uncertain and stochastic; thus, it is better to find the optimal total cost of production with fuzzy production quantity and crashing quantity. Renewable energies are important aspect of environmental sustainability, which could be incorporated to find the gap of the analysis with results. It is also necessary to work on economic analysis of MQL as compared to conventional cutting fluids with respect to time scale. Moreover, effect of MQL used as MWF in cutting operation on carbon emission can be analysed experimentally to find the positive environmental impact. Optimized technological investments to cut down carbon emission of the cutting operations will be an immediate extension to this proposed model. The output of analyses are strongly dependent on the assumptions of modelling. A single case has been developed and presented with encouraging results. It may have been of greater interest to find more results, based on a different set of assumptions to identify a lower efficiency system been cited as a comparison. Overall this research will create awareness among managers to understand the importance of carbon emissions and MQL to meet the need of today's customers for sustainable products.

Author Contributions: Muhammad Omair developed mathematical model and wrote the manuscript; Leopoldo Eduardo Cárdenas-Barrón co-supervised the research model, Biswajit Sarkar developed the idea and supervised the overall research work.

Conflicts of Interest: The authors declare no conflict of interest.

\section{Appendix A}

The list of notation for product and vendor are given in the form of indices, decision variables and parameters.

\section{Indices}

$i \quad$ vendor index, $i=1,2, \ldots I$

$j$ product index, $j=1,2, \ldots J$

$t$ index for planned time period, $t=1,2, \ldots T$

\section{Decision Variables}

$M Q_{j t} \quad$ manufactured quantity of product $j$ in period $t$ (units)

OQijt product $j$ outsourced to $i$ vendor in $t$ period (units)

CQjt quantity of product $j$, crashed in period $t$ (units) 


\section{Parameters}

$M C_{j t} \quad$ manufacturing cost for product $j$ in period $t$ (US\$/unit)

$C C_{j t} \quad$ crashing cost for production of $j$ item in period $t$ (US\$/unit)

$O C_{i j t} \quad$ outsourcing cost for product $j$ in period $t$ to vendor $i$ (US\$/unit/unit time)

$F C_{j t} \quad$ fixed cost for production of product $j$ in period $t$ (US\$)

$H C_{j t} \quad$ holding cost for product $j$ in period $t$ (US\$/unit)

$m C_{j t} \quad$ cost of maintenance for product $j$ in period $t$ (US\$)

$W C_{j t} \quad$ warehousing cost (US\$/unit)

$D_{j t} \quad$ demand for product $j$ in period $t$ (units)

$V C_{i j t} \quad$ cost of reworking for vendor $i$ and product $j$ in period $t$ (US\$/unit)

$\beta_{i j t}$ defective rate for product $j$, manufactured by i vendor in period $t$, percentage (\%)

$\alpha_{i j t} \quad$ proportion of scrap produced in defective product $j$, manufactured by vendor $i$ in period $t(\%)$

$E P_{j} \quad$ utilized electricity to manufacture product $j$ in period $t(\mathrm{kWh} / \mathrm{unit})$

$E R_{j} \quad$ electricity used to rework product $j$ in period $t(\mathrm{kWh} / \mathrm{unit})$

$E O_{i j}$ units of electricity to manufacture product $j$ from vendor $i(\mathrm{kWh} / \mathrm{unit})$

$D P_{j} \quad$ diesel fuel used to manufacture product $j$ (Lunit)

$D R_{j} \quad$ consumed diesel to rework product $j$ in period $t$ (L/unit)

$D O_{i j} \quad$ diesel used to manufacture product $j$ from vendor $i$ (L/unit)

$G P_{j}$ gasoline used to manufacture product $j\left(\mathrm{~m}^{3} /\right.$ unit)

$G R_{j} \quad$ volume of gasoline consumed to rework product $j$ in period $t\left(\mathrm{~m}^{3} / \mathrm{unit}\right)$

$G_{i j} \quad$ volume of gasoline consumed to manufacture product $j$ from vendor $i\left(\mathrm{~m}^{3} /\right.$ unit)

$M Q L_{j t} \quad$ cost of MQL for product $j$ in period $t$ (US\$/unit)

$\alpha_{1} \quad$ electricity coefficient equivalent to carbon emissions

$\alpha_{2}$ diesel fuel coefficient equivalent to carbon emissions

$\alpha_{3}$ gasoline coefficient equivalent to carbon emissions

$\gamma_{1} \quad$ unit cost of electricity (US $\$ / \mathrm{kWh}$ )

$\gamma_{2}$ cost of diesel unit (US\$/L)

$\gamma_{3}$ gasoline cost per unit (US\$ $/ \mathrm{m}^{3}$ )

$S_{j} \quad$ scrap cost (US\$/unit)

$M L_{j t} \quad$ minimum number of product $j \mathrm{~s}$ in period $t$ (units)

$M U_{j t} \quad$ maximum quantity of product $j$ in period $t$ (units)

$A S_{i j t} \quad$ minimum available product $j$ from vendor $i$ in period $t$ (units)

$B S_{i j t} \quad$ maximum product $j$ from vendor $i$ in period $t$ (units)

$\mathrm{CU}_{j t} \quad$ maximum limit for crashing quantity of product $j$ in period $t$ (units)

\section{References}

1. Forza, C.; Filippini, R. TQM impact on quality conformance and customer satisfaction: a causal model. Int. J. Prod. Econ. 1998, 55, 1-20.

2. Miller, G.; Pawloski, J.; Standridge, C.R. A case study of lean, sustainable manufacturing. J. Ind. Eng. Manag. 2010, 3, 11-32.

3. Sachs, J.D. From millennium development goals to sustainable development goals. Lancet 2012, $379,2206-2211$.

4. Jayal, A.D.; Badurdeen, F.; Dillon, O.W., Jr.; Jawahir, I.S. Sustainable manufacturing: Modeling and optimization challenges at the product, process and system levels. CIRP J. Manuf. Sci. Technol. 2010, 2, 144-152.

5. Mohammad, K.; Hassan, A.; Amin, F. Investigating the Relationship of Sustainability Factors with Project Management Success. Ind. Eng. Manag. Syst. 2016, 15, 345-353.

6. Marques, R.C.; Da Cruz, N.F.; Pires, J. Measuring the sustainability of urban water services. Environ. Sci. Policy 2015, 54, 142-151.

7. Shrivastava, P. The role of corporations in achieving ecological sustainability. Acad. Manag. Rev. 1995, 20, 936-960.

8. Omer, A.M. Energy environment and sustainable development. Renew. Sust. Eenergy Rev. 2008, 12, 2265-2300. 
9. Samaras, C.; Meisterling, K. Life cycle assessment of greenhouse gas emission from plug-in hybrid vehicles: implications for policy. Environ. Sci. Technol. 2008 , 42, 3170-3176.

10. Garcia, R.; Freire, F. Carbon footprint of particleboard: A comparison between ISO/TS 14067, GHG Protocol, PAS 2050 and Climate Declaration. J. Clean. Prod. 2014, 66, 199-209.

11. ISO/TS 14067. Greenhouse Gases: Carbon Footprint of Products Requirements and Guidelines for Quantification and Communication (Technical Specifications); International Organization for Standardization: Geneva, Switzerland, 2013.

12. ISO 14040. Environmental Management: Life Cycle Assessment: Principles and Framework; International Organization for Standardization: Geneve, Switzerland, 2006.

13. ISO 14044. Environmental Management_Life Cycle Assessment_Requirements and Guidelines; International Organization for Standardization: Geneva, Switzerland, 2006.

14. ISO 14025. Environmental Labels and Declarations e Environmental Labeling Type III: Principles and Procedures; International Organization for Standardization, Geneva, Switzerland, 2006.

15. Finkbeiner, M. Carbon footprinting-opportunities and threats. Int. J. Life Cycle. Assess. 2009, 14, 91-94.

16. Hussain, M.; Naseem Malik, R.; Taylor, A. Carbon footprint as an environmental sustainability indicator for the particleboard produced in Pakistan. Environ. Res. 2017, 155, 385-393.

17. Hillman, T.; Ramaswami, A. Greenhouse Gas Emission Footprints and Energy Use Benchmarks for Eight U.S. Cities. Environ. Sci. Technol. 2010, 44, 1902-1910.

18. Rahim, E.; Ibrahim, M.; Rahim, A.; Aziz, S.; Mohid, Z. Experimental investigation of minimum quantity lubrication (MQL) as a sustainable cooling technique. Procedia CIRP 2015, 26, 351-354.

19. Skerlos, S.J.; Hayes, K.F.; Clarens, A.F.; Zhao, F. Current advances in sustainable metalworking fluids research. Int. J. Sust. Manuf. 2008, 1, 180-202.

20. Silva, L.; Bianchi, E.; Catai, R.; Fusse, R.; Franca, T.; Aguiar, P. Study on the behavior of the minimum quantity lubricant-MQL technique under different lubricating and cooling conditions when grinding ABNT 4340 steel. J. Brazil. Soc. Mech. Sci. Eng. 2005 27,192-199.

21. Attanasio, A.; Gelfi, M.; Giardini, C.; Remino, C. Minimal quantity lubrication in turning: Effect on tool wear. Wear 2006, 260, 333-338.

22. Adler, D.; Hii, W.-S.; Michalek, D.; Sutherland, J. Examining the role of cutting fluids in machining and efforts to address associated environmental/health concerns. Mach. Sci. Technol. 2006, 10, $23-58$.

23. Dhar, N.; Ahmed, M.; Islam, S. An experimental investigation on effect of minimum quantity lubrication in machining AISI 1040 steel. Int. J. Mach. Tools Manuf. 2007, 47, 748-753.

24. Marksberry, P.; Jawahir, I. A comprehensive tool-wear/tool-life performance model in the evaluation of NDM (near dry machining) for sustainable manufacturing. Int. J. Mach. Tools Manuf. 2008, 48, 878-886.

25. Madu, C. Handbook of Environmentally Conscious Manufacturing; Springer: Berlin, Germany, 2012.

26. Wang, Y.; Li, L. Time-of-use based electricity demand response for sustainable manufacturing systems. Energy 2013, 63, 233-244.

27. Rosen, M.A.; Kishawy, H.A. Sustainable manufacturing and design: Concepts, practices and needs. Sustainability 2012, 4, 154-174.

28. Dyllick, T.; Hockerts, K. Beyond the business case for corporate sustainability. Bus. Strateg. Environ. 2002, 11, 130-141.

29. Busch, T.; Hoffmann, V.H. Emerging carbon constraints for corporate risk management. Ecol. Econ. 2007, 62, 518-528.

30. Kannan, D.; Diabat, A.; Alrefaei, M.; Govindan, K.; Yong, G. A carbon footprint based reverse logistics network design model. Resour. Conserv. Recycl. 2012, 67, 75-79.

31. Kuhtz, S.; Zhou, C.; Albino, V.; Yazan, D.M. Energy use in two Italian and Chinese tile manufacturers: A comparison using an enterprise input-output model. Energy 2010, 35, 364-374.

32. Upham, P.; Dendler, L.; Bleda, M. Carbon labelling of grocery products: Public perceptions and potential emissions reductions. J. Clean. Prod. 2011, 19, 348-355.

33. Wang, E.-J.; Lin, C.-Y.; Su, T.-S. Electricity monitoring system with fuzzy multi-objective linear programming integrated in carbon footprint labeling system for manufacturing decision making. J. Clean. Prod. 2016, 112, 3935-3951.

34. Çalışkan, H.; Kurbanoğlu, C.; Panjan, P.; Čekada, M.; Kramar, D. Wear behavior and cutting performance of nanostructured hard coatings on cemented carbide cutting tools in hard milling. Tribol. Int. 2013, 62, $215-222$. 
35. Koné, F.; Czarnota, C.; Haddag, B.; Nouari, M. Modeling of velocity-dependent chip flow angle and experimental analysis when machining $304 \mathrm{~L}$ austenitic stainless steel with groove coated-carbide tools. J. Mater. Process. Technol. 2013, 213, 1166-1178.

36. Glenn, T.F. Opportunities and market trends in metalworking fluids. Tribol. Lubr. Technol. 1998, 54, 31.

37. Thepsonthi, T.; Hamdi, M.; Mitsui, K. Investigation into minimal-cutting-fluid application in high-speed milling of hardened steel using carbide mills. Int. J. Mach. Tools Manuf. 2009, 49, 156-162.

38. Fratila, D. Evaluation of near-dry machining effects on gear milling process efficiency. J. Clean. Prod. 2009, $17,839-845$.

39. Fratila, D.; Caizar, C. Application of Taguchi method to selection of optimal lubrication and cutting conditions in face milling of $\mathrm{AlMg}_{3}$. J. Clean. Prod. 2011, 19, 640-645.

40. Biswas, P.; Sarker, B.R. Optimal batch quantity models for a lean production system with in-cycle rework and scrap. Int. J. Prod. Res. 2008, 46, 6585-6610.

41. Tayyab, M.; Sarkar, B. Optimal batch quantity in a cleaner multi-stage lean production system with random defective rate. J. Clean. Prod. 2016, 139, 922-934.

42. Inderfurth, K.; Lindner, G.; Rachaniotis, N. Lot sizing in a production system with rework and product deterioration. Int. J. Prod. Res. 2005, 43, 1355-1374.

43. Sarkar, B. An inventory model with reliability in an imperfect production process. Appl. Math. Comput. 2012, 218, 4881-4891.

44. Sarkar, B.; Sana, S.S.; Chaudhuri, K. An imperfect production process for time varying demand with inflation and time value of money-An EMQ model. Expert Syst. Appl. 2011, 38, 13543-13548.

45. Sarkar, B.; Moon, I. Improved quality, setup cost reduction, and variable backorder costs in an imperfect production process. Int. J. Prod. Econ. 2014, 155, 204-213.

46. Soni, H.; Sarkar, B.; Mahapatra, A.; Majumder, S. Lost sales reduction and quality improvement with variable lead time and fuzzy costs in an imperfect production system. RAIRO Oper. Res. 2017, doi:10.1051/ro/2016075.

47. Minjung, K. Planning Demand- and Legislation-Driven Remanufacturing for a Product Family: A Model for Maximizing Economic and Environmental Potential. Ind. Eng. Manag. Syst. 2015, 14, 159-174.

48. Saedi, M.; Saghari, S. The Balancing of Disassembly Line of Automobile Engine Using Genetic Algorithm (GA) in Fuzzy Environment. Ind. Eng. Manag. Syst. 2016, 15, 364-373.

49. Chalmers, R. Global flavor highlights NAMRC XXVII. Manuf. Eng. 1999, 123, 205-209.

50. Sardar, S.; Lee, Y.; Memon, M. A Sustainable Outsourcing Strategy Regarding Cost, Capacity Flexibility, and Risk in a Textile Supply Chain. Sustainability 2016, 8, 234.

51. Konak, A.; Coit, DW.; Smith, AE. Multi-objective optimization using genetic algorithms: A tutorial. Reliab. Eng. Syst. Saf. 2006, 91, 992-1007.

52. Keisuke, N.; Takashi, I.; Yosuke, M.; Shuling, L. Applying Genetic Algorithm for Can-Order Policies in the Joint Replenishment Problem. Ind. Eng. Manag. Syst. 2015, 14, 1-10.

53. Gembicki, F.; Haimes, Y. Approach to performance and sensitivity multiobjective optimization: The goal attainment method. IEEE Trans. Autom. Control 1975, 20, 769-771.

(C) 2017 by the authors. Licensee MDPI, Basel, Switzerland. This article is an open access article distributed under the terms and conditions of the Creative Commons Attribution (CC BY) license (http:/ / creativecommons.org/licenses/by/4.0/). 